\title{
Chapter 27 \\ Social System in Collaborative Activities for Conserving Coastal Pine Forest in Karatsu City, Kyusyu, Japan
}

\author{
Fumika Asanami and Mahito Kamada
}

\begin{abstract}
We studied the social system to maintain collaborative activities for restoring and conserving coastal pine forests in Karatsu City, Saga Prefecture, Kyushu, Japan. Governance has been structured and functioned in most conservation processes; administrative offices of the state, prefecture, and city, business sector, and Civil Society Organization have acted interdependently, and network members have continuous interaction under the management of an NPO group known as KANNE. KANNE has filled in a structural hole in the social network. KANNE plays a special role as the hub. Social ties, however, are very weak, and hence the system continuity is fragile. If KANNE stops its work, the network structure will collapse. As an internal circumstance of KANNE, most management works have been governed by the secretary-general, and any person who can act as a substitute is now absent. Installing a system to develop human resources within KANNE is important to retain conservation activities.
\end{abstract}

Keywords Local governance · NPO · Niji-no-Matsubara · Social network · Underuse of natural resources

\subsection{Introduction}

Pine forests along sandy beaches are a familiar landscape for Japanese people (Fig. 27.1). Historically, coastal pine forests have been planted and maintained by local people. In the seventeenth century, under a promotion of the government of the era, people who lived along sandy beaches started to plant pines, mainly Pinus thunbergii, to protect residential and farming areas from strong coastal wind and

F. Asanami $(\bowtie) \cdot$ M. Kamada $(\bowtie)$

Research Center for Management of Disaster and Environment, Tokushima University,

Tokushima, Japan

Department of Civil and Environmental Engineering, Graduate School of Technology, Industrial and Social Sciences, Tokushima University, Tokushima, Japan

e-mail: asanami@tokushima-u.ac.jp; kamada@ce.tokushima-u.ac.jp

(C) The Author(s) 2022

F. Nakamura (ed.), Green Infrastructure and Climate Change Adaptation,

Ecological Research Monographs, https://doi.org/10.1007/978-981-16-6791-6_27 


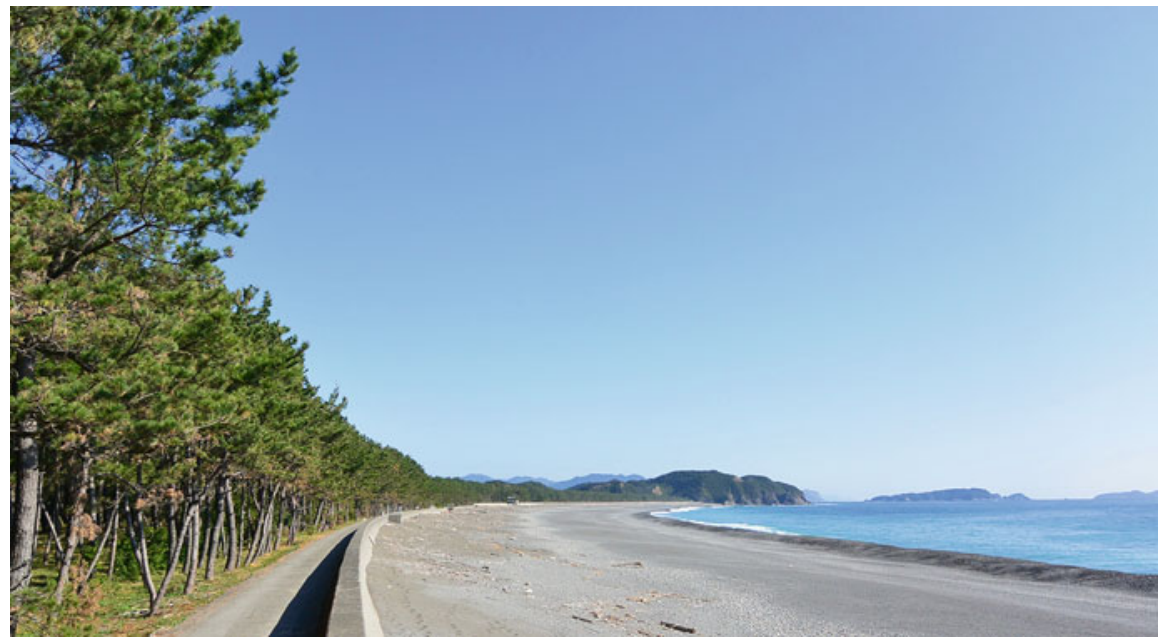

Fig. 27.1 Pine forest along a sandy beach, a typical landscape in Japan

wind-blown sand (Oda 2003; Ohta 2015). Such coastal pine forests have protected residential areas from storm surge and tsunami in addition to extreme wind because the pine is a saline tolerant species. People used to gather fallen pine needles as fuel for cooking and mushrooms as food from mature pine forests. The coastal pine forest has provided shade to people coming to swim in summer, and the landscape composed of green forest with the white beach has been beautiful scenery for both visitors and local residents. Thus, the coastal pine forest is an important green infrastructure, which provides several ecosystem services (Asanami et al. 2020), and most coastal pine forests have been designated as forest reserves by the Forest Act for keeping a function of disaster risk reduction (hereafter DRR). In addition, several forests have been preserved as scenic beauty reserves by the Act on Protection of Cultural Properties for retaining the scenic value of the area.

The situation of coastal pine forests in Japan, however, has changed and declined due to natural succession caused by the underuse of forest resources and pine-wilt disease (Yoshizaki 2012; Ohta 2015). Because both a sandy surface and sufficient sunlight are necessary for regeneration of pine trees, it is necessary to remove grass and pine needles from the forest floor in addition to shrubs colonizing the forest (Kamada et al. 1991; Kamada 2018). People used to collect pine needles and shrubs for daily fuel and sometimes cut pine trees for timber before the 1960s in Japan. In that social situation, pine forests could be continuously maintained. With the change of household fuel to petroleum and electricity due to rapid economic growth and globalization from the 1960s, people stopped using biomass, and thus forest succession has progressed (Kamada et al. 1991; Kamada 2018). In some areas, forest composition has completely changed from pine to evergreen-broad leaved forest by succession (Morisada et al. 2020). The outbreak of pine-wilt disease, which is caused by pinewood nematode (Bursaphelenchus xylophilus), has caused 
serious damage to pine forests in all regions of Japan (Kamada et al. 1991, Mamiya 1988, Yoshizaki 2012, Kamada 2018).

In order to sustain coastal pine forests, national and local governments have taken measures to protect pine trees from nematode attacks in the preserved areas. Insecticides have been sprayed to kill the longicorn beetle (Monochamus alternatus), which is the vector of pinewood nematode. In addition, dead trees containing larva of the beetles have been removed from the forests. As for the compositional decline due to succession, however, it is difficult to take measures by the government alone. It is necessary to establish a public consensus for the way of management because the image of forest composition to be conserved is different for each person. For example, people disagree with cutting shrubs. Hence, public involvement is essential to restore and conserve coastal pine forests, and governance is required to progress such works (Rhodes 1997).

We studied collaborative activities for restoring and conserving a coastal pine forest in Karatsu City, Saga Prefecture, Kyushu, Japan, and evaluated a social system from local governance perspective. The coastal pine forest is called "Nijino-Matsubara."

\subsection{Study Area}

Activities for restoring and conserving Niji-no-Matsubara were studied (Fig. 27.2). Niji-no-Matsubara is in the area of Genkai Quasi-National Park, which extends $4 \mathrm{~km}$ in length and $700 \mathrm{~m}$ in width (Fig. 27.3). It is owned and governed by the National Forestry Agency of Japan and designated as a Protected Forest to maintain DRR function and Recreation Forest for the general public. This coastal pine forest
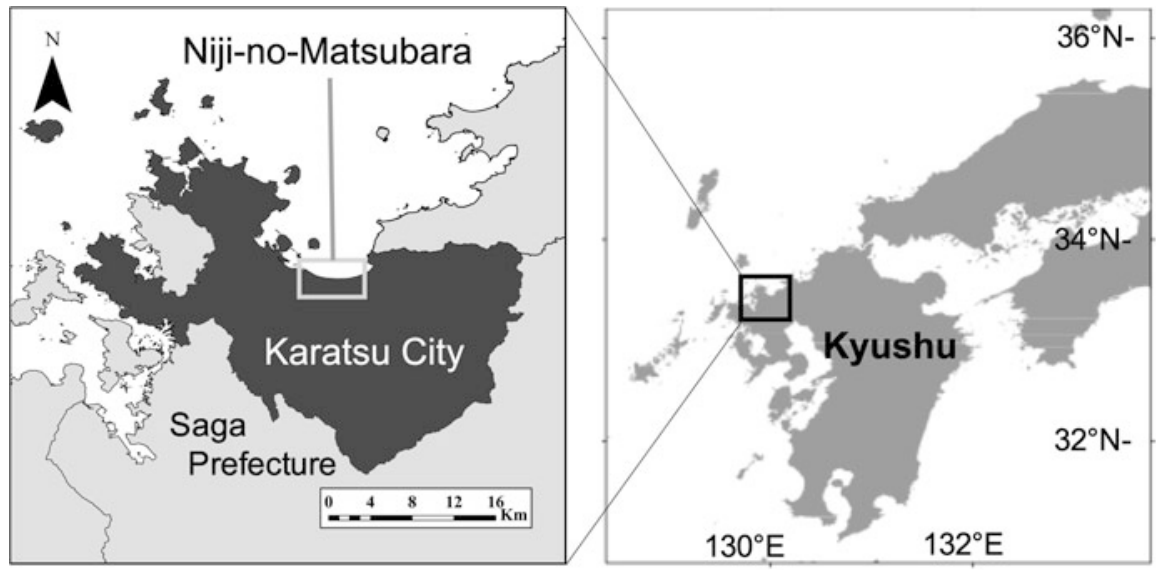

Fig. 27.2 Map of the study site 


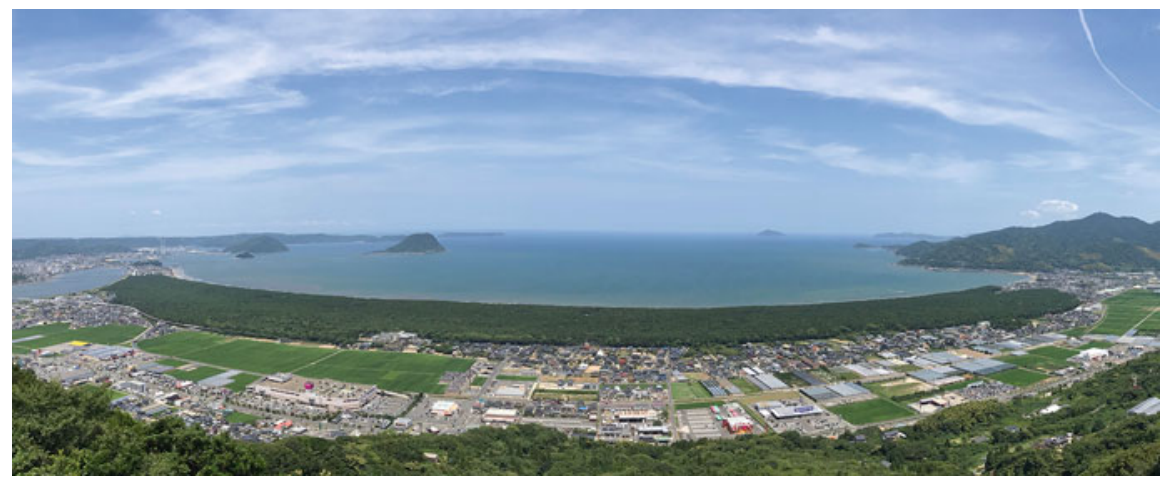

Fig. 27.3 Studied coastal pine forest, Niji-no-Matsubara

has also been designated as a Place of Scenic Beauty by the National Agency for Cultural Affairs since 1955.

Many collaborative activities for restoring and conserving "Niji-no-Matsubara" have been carried out through management by the NPO KANNE (https://www. facebook.com/npokanne).

\subsection{Methods}

In order to clarify the rolls of stakeholders, motivation and incentive, type of activities, and social system to support activities, literature documentation, focus group interview, and participant observation were conducted referring to methods of Patton (2014) and Flick (2018). Informants were (a) secretary-general and a staff of the NPO KANNE, (b) staff of Saga District Forest Office, (c) high school students, (d) junior high school students, and (e) volunteers.

\subsection{Results}

\subsubsection{Background of Restoration and Conservation Works}

Niji-no-Matsubara was governed by a feudal clan until the end of the Edo period (1603-1868) and then by the Japanese government after 1869. Local people had been forbidden to fell pine trees by the governments, while collecting pine needles had been permitted for use as daily fuel. The coastal pine forest had been maintained by the usage of local people. The pine-wilt disease occurred and caused damage to aged pine trees in 1958, and part of the Site of Scenic Beauty was invalidated in 1959 (Watanabe et al. 2006). 
In this situation, the "Council on Protective Measure for Niji-no-Matsubara (CPM)" was established in 1966. The CPM has been composed of the enterprise sector of tourism, Saga District Forest Office, Saga Prefecture, Saga Prefectural Board of Education, Saga Prefectural Police Office, Karatsu City, and Karatsu Municipal Board of Education. The mayor of Karatu City is the representative, and Tourism Division of Karatsu City plays the role of the executive office.

Vegetation succession has proceeded following the outbreak of pine-wilt disease, and dense shrubs grew in the forest around the year 2000 due to changes of fuel material and lifestyle. In order to take measures against forest decline, Saga District Forest Office made the "Basic Plan for Restoration and Conservation of Niji-no-Matsubara" in 2007 (Saga District Forest Office, Japan Forest Technology Association 2007). The "Project Team for Completing the Basic Plan for Restoration and Conservation of Niji-no-Matsubara (PT)" was formed in the CPM, and the "Execution Plan of Restoration and Conservation of Niji-no-Matsubara" was established in 2008. PT included Civil Society Organization (CSO; NPOs, citizen groups, association of parents and teachers, women's association, etc.), Saga prefectural and Karatsu municipal governments, and Saga District Forest Office (Council on Protective Measure for Niji-no-Matsubara 2014).

Because several stakeholders from different sectors are concerned with decisionmaking. People make various images of forest structures to be established and conserved for different purposes, such as disaster prevention, cultural properties, tourism, education, daily use for health of local people, etc. Hence, a process of public involvement is necessitated. The CPM has acted as a platform for the process, and the PT has been installed to obtain wider opinions from the CSO.

According to the Execution Plan, Saga District Forest Office, Saga Prefectural Office, and Karatsu City made a "Memorandum on the Preservation and Conservation of Niji-no-Matsubara" in 2008 to establish a collaborative framework to take measures against the pine-wilt disease.

Saga District Forest Office also concluded an Agreement on Forest Improvement for Recreational Use with CPM in 2008. Roles of the CPM are to (1) assist governmental work for controlling pine-wilt disease, (2) promote works for cleaning and beautifying Niji-no-Matsubara, (3) cooperate on the works for enlightening nature conservation, (4) carry out fund-raising activities, and (5) support and advice on measures to control pine-wilt disease. The CPM entrusted the management of those works to NPO KANNE. The CPM pays a trust cost of 8.1 million Japanese yen (JPY) every year, and KANNE has employed two permanent and two part-time staffs to carry out the mission.

Tasks of the KANNE for Niji-no-Matsubara conservation are to (1) manage and operate litter cleanup activities, (2) do legal proceedings to carry out activities in the area preserved by laws, (3) encourage organizations/enterprises to participate in activities, (4) call the general public to join cleanup events, and (5) support activities of CSO.

In parallel to those measures, students of Karatsu-Minami High School established "Shoro Project Team" in 2004 to revive the Shoro mushroom in the coastal pine forest. Shoro, Rhizopogon roseolus, is truffle-like mushroom that occurs in 
the coastal pine forest with a clear floor. It used to be very familiar for old people in the region. People who have experiences to collect pine leaves for fuel have also experiences collecting and eating Shoro. However, due to the colonization of shrubs into the forest floor, Shoro has disappeared, and old people have missed the mushroom.

\subsubsection{Activities Managed by NPO KANNE}

\subsubsection{Conservation Activities in the Pine Forest}

\section{Litter Cleanup Activities Through an “Adoption Program”}

Maintenance of "Niji-no-Matsubara" has been carried out in two ways. The first one, called "adoption program," is that the area to be managed is divided into small lots, and each lot is entrusted to a volunteer group and cleaned by its members.

In order to recruit participants, the secretary-general of KANNE visited enterprises individually and asked them to collaborate. According to the secretarygeneral, some enterprises were just seeking a chance to contribute to environmental activities in Karatsu City and/or Niji-no-Matsubara, and thus it was easy to obtain an agreement with them. However, it was difficult to gain collaboration from the other enterprises without any incentives. KANNE has provided an award program and introduced voluntary activities of enterprises through the web to make incentives for them.

As a result of the continuous effort of the secretary-general, the numbers of volunteer groups and persons increased from 129 and 5013 in 2011 to 219 and 7140 in 2017, respectively (Fig. 27.4). And accordingly, the cleaned area also increased from 48 ha to 56 ha. Each adopted group can do cleaning activities whenever members want. Members gather and remove pine branches and needles fell on the
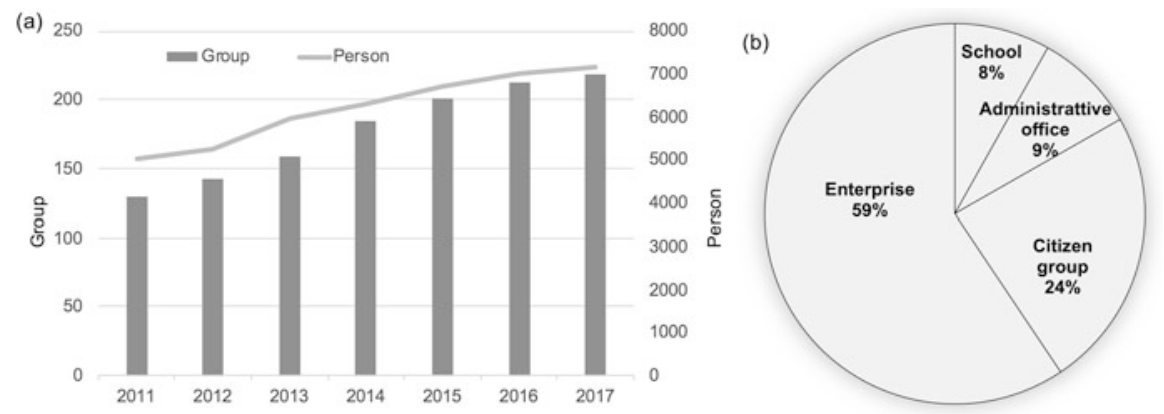

Fig. 27.4 Transition of the number of volunteer groups and persons (a) and the ratio of group/organization number in different sectors in 2019 (b) 
forest floor in the lot. As a total in 2018, 245 times of activities were conducted, and 6752 volunteers participated (NPO KANNE 2019).

\section{Litter Cleanup Event, "Keep Pine Project”}

KANNE calls on the general public to participate in events to collect and remove fallen pine needles. The events, called "Keep Pine Project (KPP)," have been held four times a year, and 300-400 volunteers have participated every time. According to the participant observation on 17 December 2017, ca. 300 volunteers cleaned the forest floor of 2 ha in $1.5 \mathrm{~h}$; the event started at 9:00 and ended at 10:30 in the morning, and five truckloads of pine matter was collected in total; the maximum load of the truck is about $4 \mathrm{~m}^{3}$ or $750 \mathrm{~kg}$ (Fig. 27.5).

For managing the event, about 30 students of Karatsu-Minami High School worked in addition to staff of the KANNE. Students said that the "Keep Pine Project" was named by former students at the high school, expecting that Niji-noMatsubara would come to be known and loved by anyone and to be conserved by collaborative activities of many people. Students of Karatsu-Minami High School visited Karatsu Commercial High School, Karatsu Higashi High School, and Higashi Karatsu Elementary School in order to explain the necessity of conservation activities and to ask them to join. Students of Junior-high and high schools joined the events as well as general citizens. The students of Karatsu Daiichi Junior High School said, "it is fun for me to come here," "here is a comfortable place," and "I will continue participating in this activity as long as I live here."

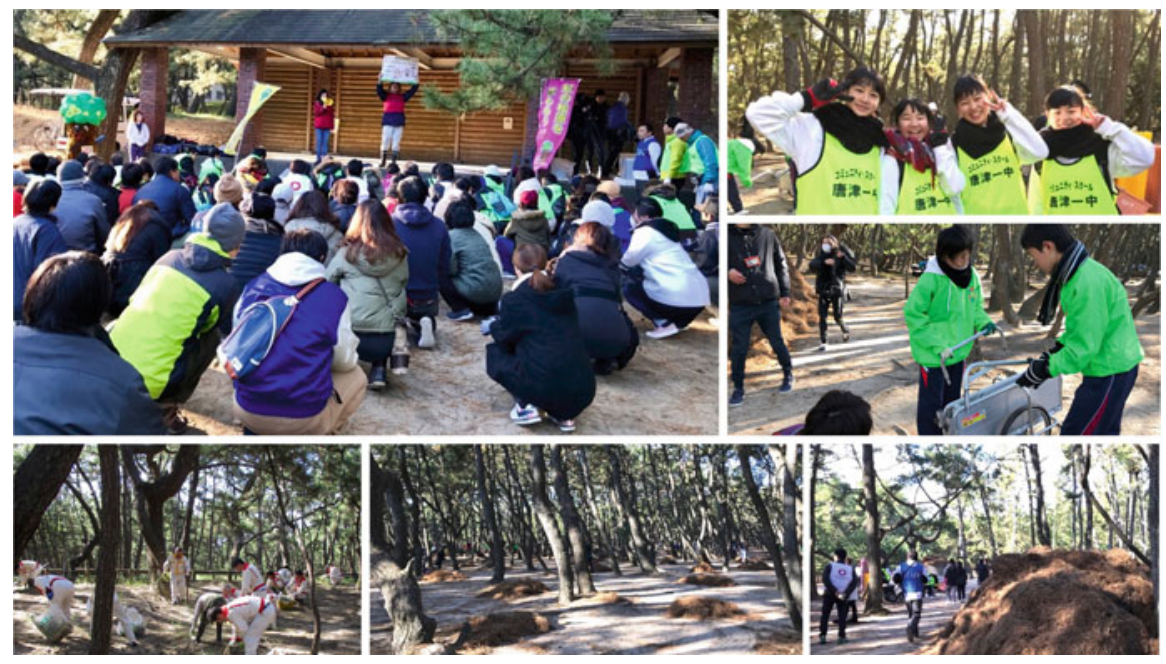

Fig. 27.5 Litter cleanup event, "Keep Pine Project" 
As a result of those litter cleanup activities, Shoro has revived in the Niji-noMatsubara.

\subsubsection{Efforts to Increase Participants in Conservation Activity}

In order to increase the number of participants in activities for Niji-no-Matsubara conservation, KANNE has provided several opportunities for the public to know about the ecological and social situation of Niji-no-Matsubara and to become interested in conservation activities.

\section{Publicity}

KANNE has produced a mascot character, named "Nijimatsu Mamoru," and made it to appear in events held in Karatsu City (Fig. 27.6). Nijimatsu Mamoru comes from the name of the coastal pine forest, Niji-no-Matsubara, and conservation activity; "Mamoru" is a Japanese word meaning conservation. A promotional song and video have also been produced. KANNE asked a singer-song writer to make a song, and the song has been sung at events and broadcast on radio programs.

KANNE has continuously published a newsletter several times a year and distributed it via the website as well as a printed version available at some public places. KANNE also posts an invitation before and report after every event on SNS such as Twitter, Instagram, and Facebook.

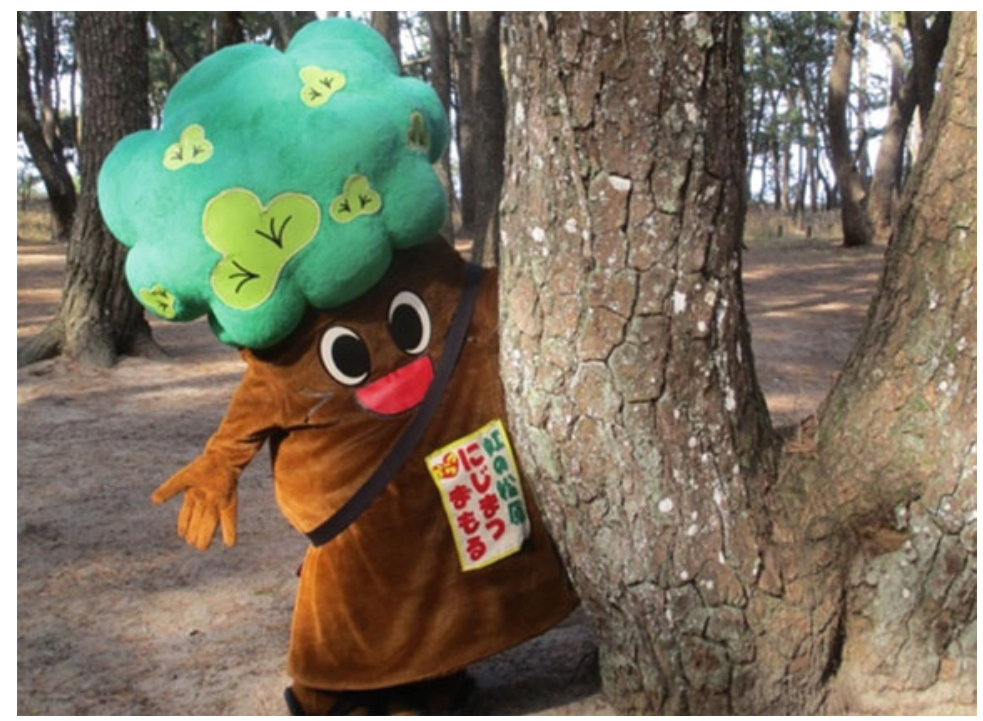

Fig. 27.6 Mascot character, “Nijimatsu Mamoru” (https://www.facebook.com/npokanne/) 


\section{Environmental Education}

KANNE has provided nature observation events for the public several times a year, such as bird watching and mushroom gathering in Niji-no-Matsubar. Picture books of plants in the pine forest and beach have been made, and anyone can download them from the website (https://npokanne.com/資料ダウンロード/). KANNE also has held workshops for crafts using pinecones at a community center.

The secretary-general of the KANNE has been asked by kindergartens and schools to give a lecture on Niji-no-Matsubara. She has visited elementary, juniorhigh, and high schools several times a year. Coloring books have been made for children and used at the lectures in kindergarten (https://npokanne.com/資料ダウ ンロード/).

Some schools, visiting Karatsu City from other districts as a school excursion, have a request to learn about the culture and social activities in the region. KANNE provides an opportunity for students at such schools to experience a litter cleanup activity.

\section{Fund-Raising}

KANNE obtains 8.1 million JPY a year from the CPM as a contract and uses about 7.5 million yen to employ staff. There is a little money left over, and an additional fund must be obtained to carry out all tasks. Hence, the staff of KANNE always make efforts to obtain subsidies and donations.

KANNE has received subsidies from several foundations such as Seven-Eleven Foundation, Japan Fund for Global Environment, and Suntory Fund for Bird Conservation, and from governments of state, Saga Prefecture, and Karatsu City.

A light truck was donated by the Karatsu Corporation Association for the use of removing pine needles collected during litter cleanup activities. Also, 360 sets of cotton work gloves for activities were donated by Suehiro Ltd. Asahi Breweries Co., Ltd. donated 1.5 million JPY, and Itoen Co., Ltd. provided bottles of tea to volunteers after events such as KPP.

\subsection{Discussion}

Stakeholders and their roles in activities for the conservation of Niji-no-Matsubara are summarized in Fig. 27.7. Saga District Forest Office, Saga Prefecture, and Karatsu City take measures under the Forest Act to protect pine trees in the Protected forest from pine-wilt disease. In this case, the purpose and goal of the work are obvious, and it is not difficult to obtain public consensus.

The CPM has acted as a platform for the process of public involvement and decision-making, and the PT has been included to obtain wider opinions from the CSO. KANNE has participated in PT as one of the NPOs and input opinions 


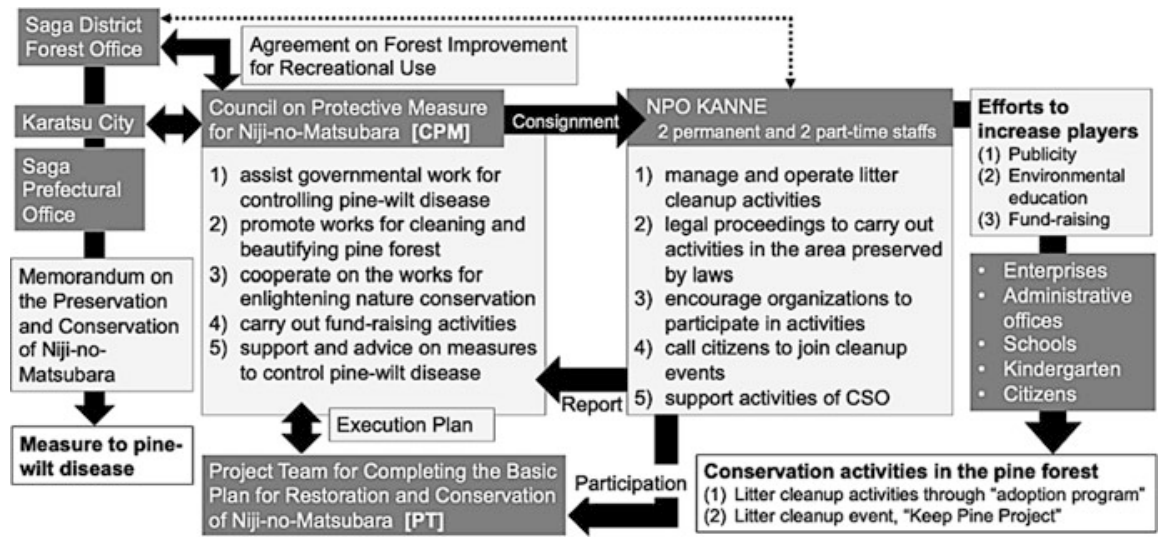

Fig. 27.7 Role of Council on Protective Measures for Niji-no-Matsubara (CPM) and NPO KANNE

regarding the way of Niji-no-Matsubara conservation. Also, KANNE has accepted the management office and acted as the hub to implement the execution plan, which was established by the PT and authorized by the CPM. In order to achieve this aim, the secretary-general of KANNE and the staff of Saga District Forest Office contact each other and exchange information frequently.

KANNE is always required to obtain funding from outside the network by way of its own effort. The incentive for the KANNE to make a continuous effort even during poor economic situations. This is both a social responsibility and pride of an NPO. KANNE was established in 2006 as an NPO working in Karatsu City for the purpose of supporting (1) community development, (2) environmental conservation activity, (3) disaster rescue operations, and (4) activity for regional security (https://npokanne.com/wp-content/uploads/2019/10/ teikan.pdf). Working as a management office of the activities is well matched to KANNE's purpose.

Rhodes (1997) summarized the characteristics of governance as follows: (1) interdependence between organizations as boundaries between public, private, and voluntary sectors became shifting and opaque; (2) continuous interactions between network members, caused by the need to exchange resources and negotiate shared purposes; (3) game-like interactions, rooted in trust and regulated by rules of the game negotiated and agreed by network participants; and (4) a significant degree of autonomy from the state. Networks are not accountable to the state as they are selforganizing. Although the state does not occupy a sovereign position, it can indirectly and imperfectly steer networks.

According to Rhodes's criteria, it seems that governance is structured and functioned in almost all conservation processes. (1) Administrative offices of the state, prefecture, and city, business sector, and CSO have acted interdependently. (2) Network members have continuous interaction under the management of KANNE. (3) Staff of KANNE and Saga District Forest Office frequently and freely discuss and make decisions on managing conservation activities. In litter cleanup 
events such as KPP, high school students and KANNE's staff also have game-like interactions. The CPM, however, acts only as a platform for the exchange of official or governmental information and does not have game-like interactions among the members. (4) Activities of volunteers are independent of the state, although a framework for the treatment of the area preserved by laws is set by the Forestry Agency of Japan and National Agency for Cultural Affairs.

From a viewpoint of social networks, KANNE has filled a structural hole in the social network (Burt 1992). KANNE plays a special role as the hub, but social ties are very weak and hence system continuity is fragile. If KANNE ceases its work, the network structure will collapse. As an internal circumstance of KANNE, most management works have been carried out by the secretary-general, and a person who can act as a substitute is now lacking. Creating a system to develop human resources within KANNE is important to maintain conservation activities.

Another flaw in the governance is little concern and less responsibility of the CPM to the management process, and little opportunities for KANNE to advocate new policy/plan for completing the PDCA cycle. In order to build a more sustainable governance system, participation of the CPM in the PDCA process is strongly recommended as well as setting the KANNE to even relationship with CPM, not as a subcontractor.

NPOs play important roles in governance for sustaining regional ecosystems as common property in Japan (Kamada 2018). External and internal situations of the NPOs are probably similar to KANNE, or worse. Recognition and support of local government and society to develop stable NPOs is required in order to establish a mature and reliable governance system for maintaining natural and social capital.

Acknowledgments We would like to express our gratitude to Ms. Wakako Fujita, the secretarygeneral of NPO KANNE, and Mr. Hitoshi Hida, a staff of Saga District Forest Office, for their cooperation on interview survey and for help at participation observation. We also thank students of Saga Prefectural Karatsu-Minami High School, Karatsu Municipal Daiichi Junior High School, and Karatsu Municipal Hamatama Junior High School for their cooperation in the litter cleanup event. This study was supported by the Environment Research and Technology Development Fund (JPMEER20184005).

\section{References}

Asanami F, Ito K, Kamada M (2020) Self-managerial activity by local people for keeping coastal pine forest and complemental policy of Fukutsu City, Fukuoka prefecture, Japan. Landsc Ecol Manag 25:53-68. (in Japanese with English Abstract)

Burt RS (1992) Structural holes: the social structure of competition. Harvard University Press, Cambridge

Council on Protective Measure for Niji-no-Matsubara (2014) Execution Plan of Restoration and Conservation of Niji-no-Matsubara, 1st revised Edition. (in Japanese)

Flick U (2018) An introduction to qualitative research, 6th edn. SAGE Publications Ltd., Los Angeles, p 696 
Kamada M (2018) Satoyama landscape of Japan -past, present, and future. In: Hong S-K, Nakagoshi N (eds) Landscape ecology for sustainable society. Springer, Cham, pp 87-109. https://doi.org/10.1007/978-3-319-74328-8_6

Kamada M, Nakagoshi N, Nehira K (1991) Pine forest ecology and landscape management: a comparative study in Japan and Korea. In: Nakagoshi N, Golley FB (eds) Coniferous Forest ecology from an international perspective. SPB Academic Publishing, The Hague, pp 43-62

Morisada S, Nozaki T, Ogawa M, Kamada M (2020) Succession from pine forest to evergreen broad-leaved forest at Ohki coastal beach in Kochi prefecture, Shikoku, Japan. Landsc Ecol Manag 25:75-86. (in Japanese with English Abstract)

NPO KANNE. 2019. Business report on the 2018 fiscal year. (in Japanese)

Oda T (2003) The people who made the coastal forest (Kaigan-rin o tsukutta hitobito). Hokuto Publisher, Tokyo, p 254. (in Japanese)

Ohta T (2015) Nowadays and future for coastal forests. J Japanese Soc Revegetat Technol 41:332333. (in Japanese)

Patton MQ (2014) Qualitative evaluation and research methods, 4th edn. SAGE Publications Ltd., London, p 832

Rhodes RAW (1997) Understanding governance - policy networks, governance, reflexivity and accountability. Open University Press, Maidenhead, p 235

Saga District Forest Office, Japan Forest Technology Association (2007) Survey report on measures for conservation and restoration of Niji-no-Matsubara. Saga District Forest Office, p 68. (in Japanese)

Watanabe T, Yokouchi K, Okada T, Mitsumizo H (2006) A study on the landscape management strategy in "Niji-no-Matsubara": relationship between the management and the landscape value of pine forest. J Architect Infrastruct Environ 1:107-114. (in Japanese)

Yoshizaki S (2012) Contemporary problems relating to the coastal forest in Japan. Water Sci 56(3):14-27. (in Japanese)

Open Access This chapter is licensed under the terms of the Creative Commons Attribution 4.0 International License (http://creativecommons.org/licenses/by/4.0/), which permits use, sharing, adaptation, distribution and reproduction in any medium or format, as long as you give appropriate credit to the original author(s) and the source, provide a link to the Creative Commons license and indicate if changes were made.

The images or other third party material in this chapter are included in the chapter's Creative Commons license, unless indicated otherwise in a credit line to the material. If material is not included in the chapter's Creative Commons license and your intended use is not permitted by statutory regulation or exceeds the permitted use, you will need to obtain permission directly from the copyright holder. 